\title{
Progress in Molecular Imaging in Endoscopy and Endomicroscopy for Cancer Imaging
}

\author{
Supang Khondee ${ }^{1,3}$ and Thomas D. Wang ${ }^{1,2 *}$ \\ ${ }^{1}$ Department of Medicine, University of Michigan, Ann Arbor, MI, USA \\ ${ }^{2}$ Department of Biomedical Engineering, University of Michigan, Ann Arbor, MI, USA \\ ${ }^{3}$ School of Pharmaceutical Sciences, University of Phayao, Phayao, Thailand
}

Submitted July 2012. Accepted for publication November 2012.

\begin{abstract}
Imaging is an essential tool for effective cancer management. Endoscopes are important medical instruments for performing in vivo imaging in hollow organs. Early detection of cancer can be achieved with surveillance using endoscopy, and has been shown to reduce mortality and to improve outcomes. Recently, great advancements have been made in endoscopic instruments, including new developments in optical designs, light sources, optical fibers, miniature scanners, and multimodal systems, allowing for improved resolution, greater tissue penetration, and multispectral imaging. In addition, progress has been made in the development of highly-specific optical probes, allowing for improved specificity for molecular targets. Integration of these new endoscopic instruments with molecular probes provides a unique opportunity for significantly improving patient outcomes and has potential to further improve early detection, image guided therapy, targeted therapy, and personalized medicine. This work summarizes current and evolving endoscopic technologies, and provides an overview of various promising optical molecular probes.
\end{abstract}

Keywords: endoscopy, endomicroscopy, optical imaging, molecular probes

\section{INTRODUCTION}

Molecular imaging is an important emerging technology for improving clinical management of cancer and for advancing laboratory-based methodologies to study cancer biology. Molecular imaging can play an important role in clinical care of cancer by improving our ability to perform risk stratification, screening, surveillance, guiding biopsy, staging, prognosis, planning and guidance of therapy, monitoring therapy efficacy, and assessing recurrence. With rapid technological advances, the future role

*Corresponding author: Thomas D. Wang, Associate Professor of Medicine and Biomedical Engineering, Division of Gastroenterology, University of Michigan, 109 Zina Pitcher Place, BSRB 1522, Ann Arbor, MI 48109. Phone: (734) 936-1228. Fax: (734) 647-7950. Email: thomaswa@umich.edu. Other author: skhondee@med.umich.edu. 
for molecular imaging may also include pre-symptomatic detection, targeted therapy, and personalized medicine [1].

Conventional imaging modalities such as magnetic resonance imaging (MRI), positron emission tomography (PET), single-photon emission computed tomography (SPECT), computed tomography (CT), and ultrasound (US) have distinct advantages and limitations. MRI detects the relaxation times of magnetic dipoles, such as hydrogen atoms in water and organic compounds, after a radiofrequency pulse, and then generates MR signals. MRI offers spatial resolution on the millimeter scale with simultaneous physiological and anatomical correlation. However, MRI requires long scan and post processing times and has relatively low sensitivity, thus requiring high doses (typically micrograms to milligrams) of magnetic contrast agents. PET and SPECT record highand low-energy $\gamma$ - rays, respectively, emitted from within the body. These imaging modalities have very high sensitivity but relatively low spatial resolution. CT images are acquired based on the extent of X-ray absorbance by tissue. CT provides highresolution anatomical images especially for bones and tumors, but has poor soft tissue resolution and limited molecular imaging applications. US has high temporal resolution, can achieve imaging in real time, and is inexpensive and safe. However, the use of US in molecular imaging has so far been limited to intravascular targets. Thus, these conventional imaging modalities have relatively low spatial resolution in comparison to optics and some risk due to radiation. Furthermore, most of these techniques require a significant cost for initial start-up, maintenance, and infrastructure development, limiting access to patients in less developed countries.

Optical imaging is an emerging technology that offers several unique advantages and is being combined with molecular probes to improve specificity. Optics is non-ionizing, and can provide resolution on the micron scale, allowing for sub-cellular visualization [2]. Light over a broad range of colors allows for multispectral techniques to visualize multiple molecular targets simultaneously. Therefore, heterogeneous gene expression patterns found in tumors can be better characterized. Multispectral imaging requires the use of several molecular probes that have different emission wavelengths but similar binding kinetics, and can achieve greater detection sensitivity as a panel. Another advantage of optical imaging is the ability to collect images in real time in comparison to other imaging modalities, such as MRI and PET.

Endoscopes are thin, flexible instruments that provide a macroscopic view of the large mucosal surfaces in hollow organs internal to the human body. Miniature optics with large divergence angles is used that can generate a large field-of-view (FOV) with high spatial resolution. Endomicroscopy employs high numerical aperture (NA) optics to provide a small FOV with micron-level resolution for observing sub-cellular features. It requires scaling down the size of a conventional microscope design into a miniature package [3]. These instruments provide a unique opportunity for early cancer detection and prevention by allowing therapy (biopsy or resection) to be performed concurrently with diagnosis.

Several endoscopic imaging methods have been developed for imaging mucosa over a large field-of-view (FOV). White light endoscopy (WLE) uses visible reflectance from the mucosal surface, and is limited to visualizing flat and depressed lesions that 
have minimal morphological changes [4]. Narrow band imaging (NBI) uses optical filters to reduce (narrow) the spectral bandwidth of the illumination in the green regime to enhance absorption from hemoglobin to improve visualization of vascular patterns and fine mucosal surface textures, but the results for early detection of cancer vary. Autofluorescence imaging (AFI) uses blue excitation (390-470 nm) to detect fluorescence from endogenous fluorophores, such as collagen, flavins, and porphyrins; however, clinical studies have demonstrated lack of specificity [5, 6].

Novel optical designs and scanning mechanisms are being developed to improve imaging performance for both endoscopy and endomicroscopy. This paper highlights some of these emerging technologies, focusing on recent advances in instrumentation as well as optical molecular probes. The aim of this review is to outline promising endoscopic instruments, molecular probe platforms, and integration of these technologies for cancer imaging. Section 2 summarizes existing endoscopic technologies, categorized as macroscopic and microscopic approaches, including preclinical and clinical results for each technology. The following sections address molecular probes for optical imaging and recent endoscopic molecular imaging.

\section{ENDOSCOPIC INSTRUMENTS FOR MOLECULAR IMAGING}

\subsection{Endoscope (Macroscopic Imaging) - Scanning Fiber Endoscope}

The scanning fiber endoscope (SFE) scans in a spiral pattern by a tubular piezoelectric actuator to create an image with a large FOV. Red, green, and blue (RGB) laser light (440, 532, and $635 \mathrm{~nm}$ wavelengths) is delivered through the scanning fiber and focused onto the mucosal surface with a multi-lens assembly located in the distal tip. The reflectance and fluorescence light is collected by a ring of multimode optical fibers arranged around the perimeter of the instrument. The SFE imaging technology was first developed for early detection of cancer in the esophagus, pancreatic duct, and peripheral airways using reflected white light $[2,7]$.

Recently, the SFE technology has been adapted for collection of fluorescence to perform molecular imaging. In a recent study, SFE demonstrated potential for use in molecular imaging [8]. The detection system of the multispectral endoscope (Figure 1A) uses longpass (wavelength $\left.\lambda_{\mathrm{LP}}=450 \mathrm{~nm}\right)$ and notch $\left(\lambda_{\mathrm{N} 1}=532 \mathrm{~nm}\right.$ and $\lambda_{\mathrm{N} 2}=632.8 \mathrm{~nm}$ ) filters to reject the reflectance component (RGB laser excitation) of the light from the collection fibers. The distal tip of multispectral SFE with $1.6 \mathrm{~mm}$ outer diameter and $10 \mathrm{~mm}$ rigid distal tip is shown in Figure 1B. To prove the multispectral and molecular imaging concept, three different peptides that bind specifically to colonic dysplasia were labeled with three different fluorescent dyes that have excitation wavelengths matching the three laser excitation wavelengths. Diethylaminocoumarin-3-carboxylic acid (DEAC) with absorption and emission peaks at 432 and $472 \mathrm{~nm}$, 5-carboxytetramethylrhodamine (TAMRA) with absorption and emission peaks at 541 and $568 \mathrm{~nm}$, and CF633 with absorption and emission peaks at 630 and $650 \mathrm{~nm}$ were used. Images of KCCFPAQ-DEAC (blue), AKPGYLS-TAMRA (green/yellow), LTTHYKL-CF633 (red), and unlabeled peptide droplets collected with a multispectral SFE are shown in Figure 1C-D. This study demonstrated the capability of the multispectral SFE to simultaneously detect multiple labeled peptides over the visible spectrum. 
(a)

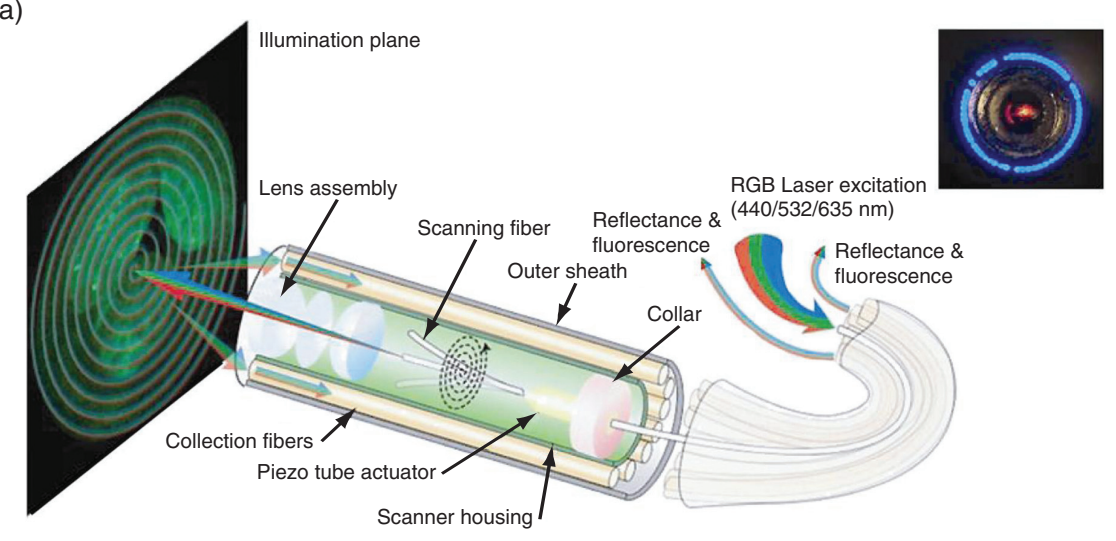

(b)

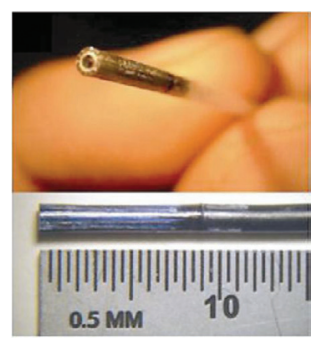

(c)

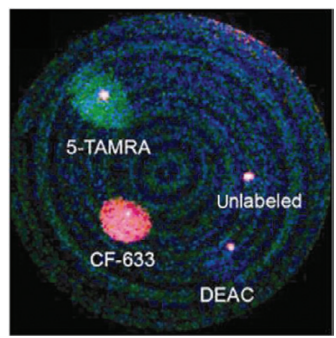

(d)

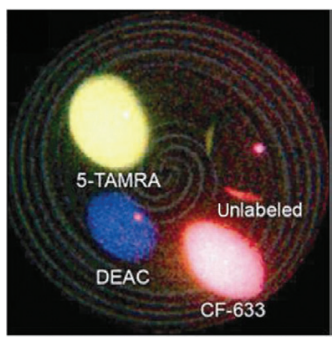

Figure 1. (A) Multispectral scanning fiber endoscope (SFE). Inset shows illumination fiber (red) and a ring of multimode optical fibers for light collection (blue). (B) En face (top) and side-view (bottom) of distal tip of multispectral SFE. (C, D) Images of labeled and unlabeled peptide droplets at concentrations of $1 \mu \mathrm{M}(\mathrm{C})$ and $100 \mu \mathrm{M}$ (D). Used with permission [8].

\subsection{Endomicroscope (Microscopic Imaging)}

\subsubsection{Confocal Endomicroscope}

A confocal endomicroscope performs high resolution optical sectioning over a small FOV, similar to a laboratory microscope, but in a package that is scaled down in size to millimeter dimensions. A single mode optical fiber placed on the main optical axis between the objective lens and the detector acts as a "pinhole" to allow only the light from a small focal volume below the tissue surface to be collected. A high NA objective lens is used to illuminate and collect light to achieve subcellular resolution with maximum light collection. For endoscope compatibility, the diameter of the overall package must be reduced to $\sim 5 \mathrm{~mm}$ or less. As a result, the working distance (WD), FOV, and tissue penetration depth are usually reduced. Confocal endomicroscopes can be used to guide biopsies, and have been demonstrated in a number of clinical studies to detect cancer in the digestive tract, bladder, cervix, ovary, oral cavity, and lungs, with some recent findings from human clinical trials summarized below. 


\subsubsection{Single Axis Architecture}

Two confocal endomicroscopes that use the single axis architecture have been commercialized and employed in the clinics. In the first approach, a fiber scanning design (Optiscan Pty Ltd, Victoria, Australia) is integrated into the insertion tube of a medical endoscope (EC-3870K, Pentax Precision Instruments, Tokyo, Japan). A semiconductor laser provides excitation at $488 \mathrm{~nm}$ wavelength. The distal tip of the fiber is laterally scanned by a tuning fork mechanism, and axial scanning is performed by a shape memory alloy actuator that moves the focal volume over a distance of up to $250 \mu \mathrm{m}$ below the tissue surface. This system uses an objective that has an NA $\sim 0.6$, yielding a transverse and axial resolution of 0.7 and $7 \mu \mathrm{m}$, respectively.

Kiesslich et al. demonstrated this endomicroscope in the colon in 69 patients. After intravenous injection of fluorescein sodium, neoplastic changes were identified with a sensitivity of $97.4 \%$ and specificity of $99.4 \%$ [9]. In another study of 9 gastric cancer patients, neoplastic changes could be identified with a sensitivity of $92.6 \%$ and $88.8 \%$, specificity of $100 \%$ and $100 \%$, and accuracy of $96.3 \%$ and $94.4 \%$ on evaluation by an endoscopist and a pathologist, respectively [10]. However, comparing confocal endomicroscopy with other techniques such as NBI and chromoendoscopy, the advantage of confocal imaging in terms of accuracy in identifying colorectal polyps was found to vary from study to study [11, 12].

Another approach is based on a coherent fiber bundle. A miniprobe (Mauna Kea Technologies, Paris, France) passes through the standard instrument channel of medical endoscopes. Excitation is also provided at $488 \mathrm{~nm}$ as in the first approach, and scanning is performed at the proximal end of the fiber bundle in the instrument control unit using a set of oscillating and galvo mirrors. In this design, axial scanning is not available, and thus optical sections at different depths are achieved by using separate miniprobes that have different working distances. An objective with NA of $\sim 0.6$ is employed to provide a transverse and axial resolution of $2.5-5 \mu \mathrm{m}$ and $15-20 \mu \mathrm{m}$, respectively.

This instrument is much smaller in diameter, and was demonstrated in the biliary ducts in 37 patients who underwent endoscopic retrograde cholangiopancreatography (ERCP) for bile duct stone removal or bile duct stenosis. Malignant strictures were clearly differentiated from normal common bile duct walls using the CholangioFlex probe. Neoplasia was predicted with $83 \%$ sensitivity and $75 \%$ specificity [13]. In a similar study, the Cellvizio CholangioFlex probe was used in a 102-patient study to develop and validate a standard descriptive classification for images collected in the pancreaticobiliary system [14]. A consensus definition of the specific criteria of biliary and pancreatic imaging findings for indeterminate strictures was developed.

Probe-based confocal endomicroscopy has also been employed for molecular imaging. A heptapeptide, that contains a VRPMPLQ sequence, was identified using phage display technology [15]. This peptide was labeled with fluorescein, applied topically to the colonic mucosa of patients undergoing routine colonoscopy, and showed specific binding to sporadic human colorectal adenomas. The peptide bound to dysplastic colonocytes with $81 \%$ sensitivity and $82 \%$ specificity. 


\subsubsection{Dual-Axes Architecture}

In the dual-axes design, two optical fibers and two low-NA objectives are employed to separate the illuminating and collecting light paths, resulting in a sub-cellular resolution in three dimensions (3D), longer WD, and deeper tissue penetration [16]. The longer WD also allows for post-objective scanning, resulting in scalability and a larger FOV. Scanning is performed with a tiny micro-mirror fabricated using Micro Electro Mechanical Systems (MEMS) mirror technology. This instrument can be scaled down to millimeter dimensions.

Piyawattanametha et al. developed an MEMS-based dual-axes confocal endomicroscope with a 5.5-mm outer diameter for clinical imaging in the gastrointestinal tract [17]. Figure 2A shows miniature dual-axes scan head design with two collimated beams focused by a parabolic mirror. Scanning electron micrograph (SEM) of MEMS scanner is shown in Figure 2B. Figure 2C depicts the endomicroscope scanhead, including (a) two collimated beams focused by a parabolic mirror and (b) the endomicroscope with the 2D MEMS scanner. Figure 2D shows the endomicroscope passed through a 6-mm instrument channel of a special medical endoscope. This system was demonstrated both ex vivo and in vivo after topical application of indocyanine green, a near-infrared fluorescence dye. Real-time fluorescence imaging was performed in human colon, and Figure 2E shows a sequence of post-processed, mosaiced images

(a)

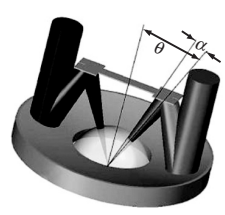

(d)
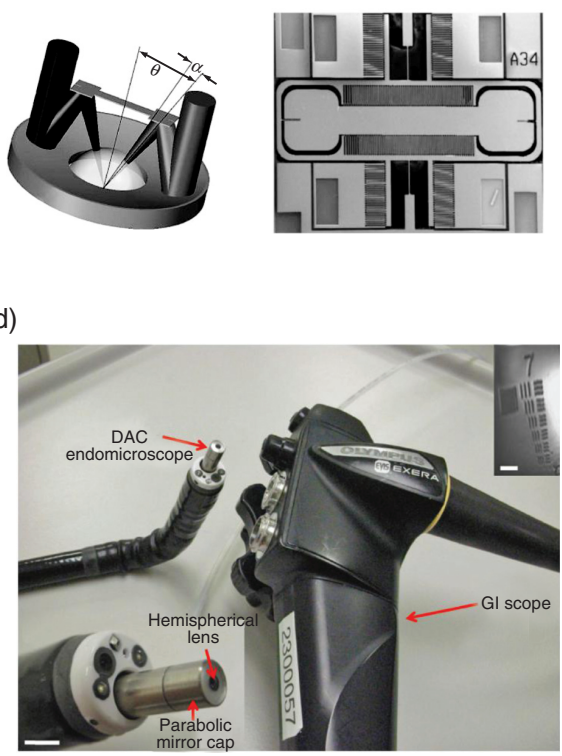

(c)

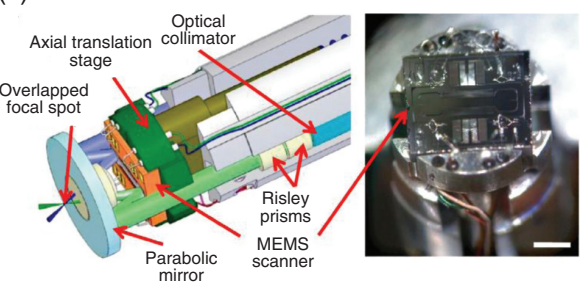

(e)

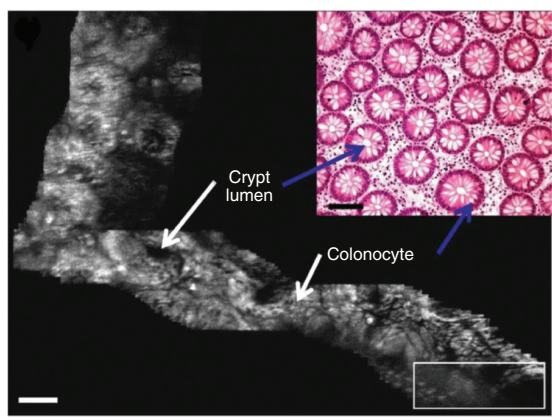

Figure 2. MEMS dual-axes confocal endomicroscope. (A) Miniature dual-axes scan head. (B) SEM of 2D MEMS scanner. (C) Endomicroscope scanhead. (D) Dual-axes confocal (DAC) endomicroscope delivered through an instrument channel of gastrointestinal (GI) endoscope. (E) A mosaic of normal colonic mucosa; inset shows histology (H\&E). Scale bar $=100 \mu \mathrm{m}$. Used with permission $[17,18]$. 
of normal colonic mucosa acquired at a depth of $60 \mu \mathrm{m}$ and a representative histological (H\&E) image of normal colonic mucosa.

\subsubsection{Multi-photon Endomicroscope}

Multi-photon-excited fluorescence imaging techniques have been developed to overcome limitations in tissue penetration depth experienced with single photon excitation. Multi-photon imaging systems use ultra-fast (femtosecond) laser pulses with near-infrared (NIR) excitation (typically 700 to $1040 \mathrm{~nm}$ ), resulting in emission in the visible regime. As a result, multi-photon excitation systems offer key advantages that include intrinsic optical sectioning ability (owing to the non-linear excitation process and the restricted excitation volume), deeper tissue penetration depth, reduced out-of-focus photobleaching, and fewer associated phototoxicities. Multi-photon imaging has also attracted attention due to its ability to directly image tissue without the use of contrast agents. The intrinsic imaging contrast results from induced autofluorescence provided by endogenous fluorophores such as NADH, flavin and collagen. Besides providing high resolution imaging of tissue morphology, imaging based on endogenous fluorophores can provide clues about metabolic activity and matrix changes associated with diseases [19]. Safety is a key issue with endogenous fluorophores. Therefore, some factors such as endoscope design, laser intensity and tissue type should be considered carefully to avoid photobleaching, cell damage, and mutagenicity [20].

A number of different multi-photon endomicroscope designs have been developed [21-23] to investigate structure, function and molecular events [24, 25]. In one study, goblet cells, signifying the presence of intestinal metaplasia, were imaged using confocal and two-photon-excited fluorescence endomicroscopes [26]. Images collected with the two-photon endomicroscope exhibited higher resolution and contrast at each depth from the mucosal surface to $176 \mu \mathrm{m}$ below in mouse intestinal specimens. In addition, the two-photon endomicroscope showed superior sectioning ability and less photobleaching. Some systems were not primarily designed for hollow organ imaging, but for biopsy guidance and/or replacement. In recent studies, an endoscope that uses a gradient index (GRIN) lens was developed for multi-photon and second harmonic generation (SHG) imaging, as shown in Figure 3A. The total system length was $26.9 \mathrm{~cm}$ with a rigid distal tip that is $1.2 \mathrm{~mm}$ in outer diameter, and $\sim 8 \mathrm{~cm}$ in length (Figure 3B). This GRIN endoscope was validated in vivo in anesthetized rats [27]. An image of unstained superficial kidney renal cortex showed dark renal interstitium (RI), dark cellular nuclei (N), bright intrinsic fluorescent cytoplasm (CY), renal tubules (RT), renal capsule (RC), and dark blood filled lumen (L) inside the renal tubules (Figure 3C). This system has several advantages over flexible multi-photon endoscope. GRIN lens is inexpensive, small, and could be inserted into needles as small as 22 gauge. It also offered uniformed scan. In another recent study, multifocal multiphoton endoscope was developed to achieve fast frame rate without reducing signal-to-noise ratio per frame, and axialsectioning [22]. The endoscope has a 3-mm-outer diameter and 4-cm-rigid length, and acquired images at 4 frames per second per focal plane with lateral and axial resolutions of 0.8 and $10 \mu \mathrm{m}$, respectively. The system was tested using excised mouse lung. 
(a)

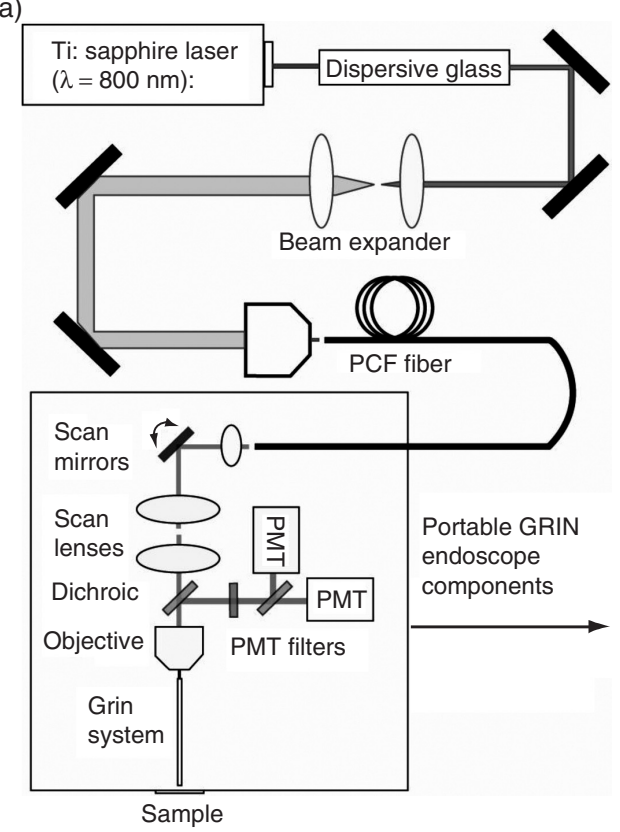

(b)

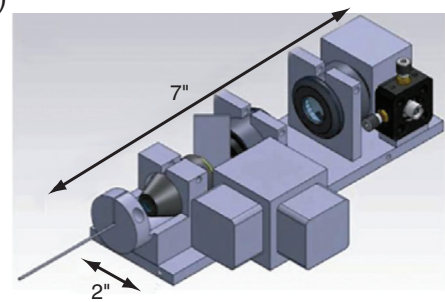

(c)

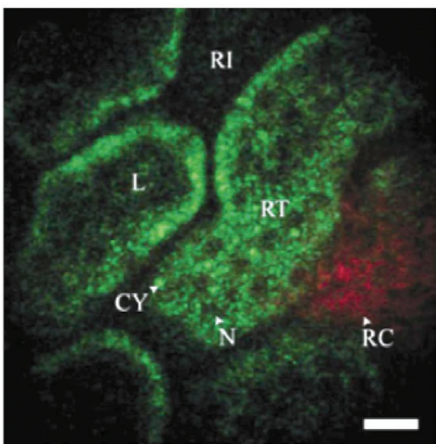

Figure 3. An optical diagram (A) and appearance (B) of portable GRIN endoscope. (PMT: photomultiplier tube, PCF: plastic-coated glass fibers.) (C) An unstained image of rat kidney renal cortex obtained using the GRIN endoscope; scale bar is $20 \mu \mathrm{M}$. Used with permission [27].

In addition, an integrated optical coherence tomography (OCT) and two-photon fluorescence endoscope was also developed for simultaneously acquiring tissue morphological and molecular information [28]. The system was tested using cell culture and excised mouse adipose tissue. In another study, a hybrid confocal and two-photon endomicroscope was developed, and demonstrated images of blood vessels labeled with rhodamine-B-dextran conjugates in a mouse ear [3]. Additionally, a high-NA endomicroscope was coupled to a multi-photon tomograph, DermaInspect. This integrated system has been used to detect skin cancer in a label-free manner [29], screen topically applied cosmetics and pharmaceuticals [30], and perform optical sectioning in pre-clinical studies [3].

\subsubsection{Photoacoustic Endoscope}

Recently, endoscopes have been developed based on the photoacoustic process [31], where energy from short laser pulses delivered into tissue is absorbed and converted into sound, resulting in deeper tissue penetration. Ultrasonic transducers collect the acoustic waves to form images. A hybrid optical/photoacoustic system has been demonstrated in a murine model using proflavine as a fluorescence contrast agent. An experimental setup for a hybrid photoacoustic and fluorescence endomicroscopic system is shown in Figure 


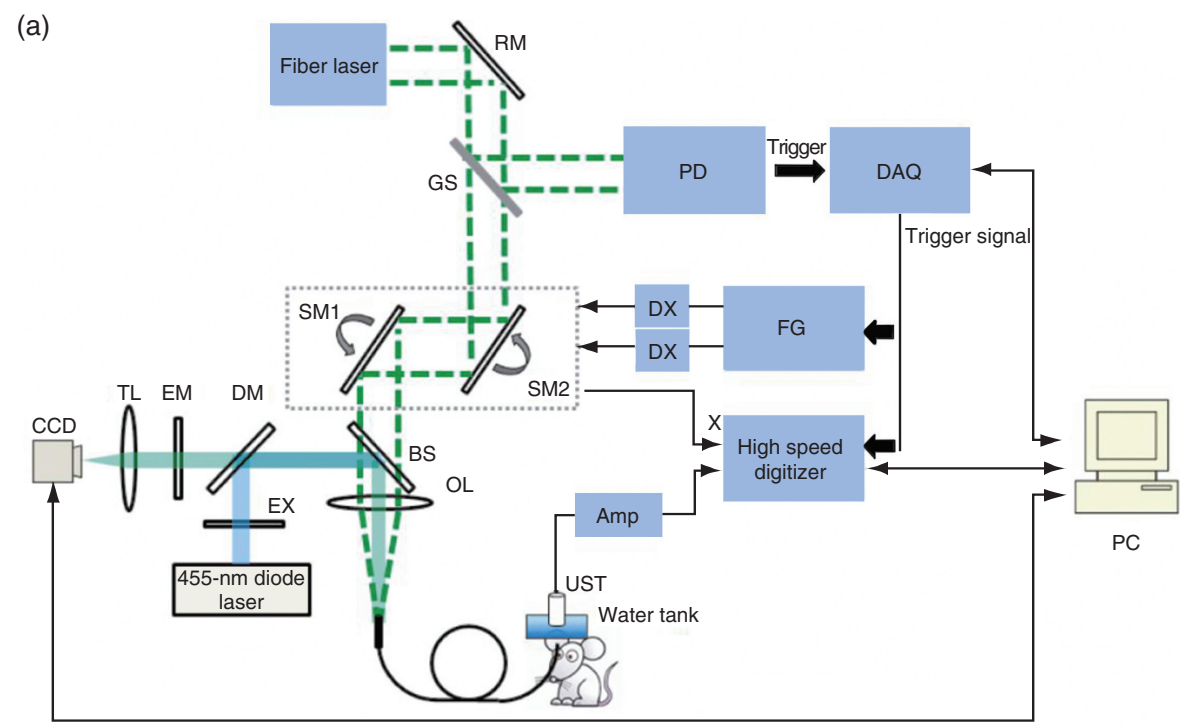

(b)

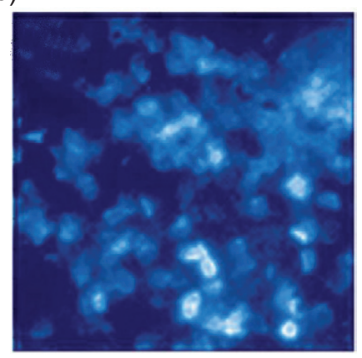

(c)

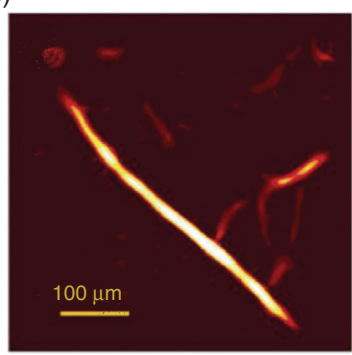

(d)

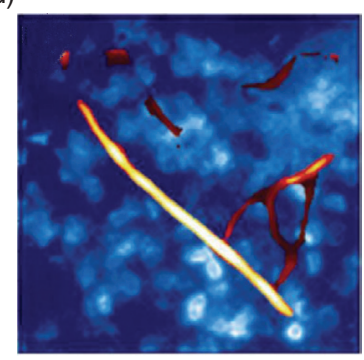

Figure 4. (A) Schematic diagram of the combined photoacoustic and fluorescence endomicroscopy imaging system. (RM: reflective mirror, GS: glass slide, PD: photodiode, DAQ: data acquisition, S/M 1 / 2: scanning mirrors 1 and 2, FG: function generator, DX/Y: galvanometer scanning mirror divers, BS: beam splitter, OL: objective lens, UST: ultrasound transducer, Amp: amplifier, CCD: charged-couple device, TL: tube lens, EM: emission filter, DM: dichroic mirror, EX: excitation filter.) (B) Fluorescence image of a mouse ear. (C) Optical-resolution photoacoustic endomicroscopy (OR-PAME) image of the same mouse ear. (D) Coregistered image of (B) and (C). Used with permission [31].

4A. The system collected fluorescence images to provide cellular morphology (Figure 4B) and photoacoustic (Figure 4C) images to visualize blood vessel structures. The two images were co-registered to provide multimodal information (Figure 4D). This technique may be used to monitor angiogenesis (the formation of new blood vessels) and effects of anti-cancer drugs on both cells and the microcirculation. 


\section{RECENT ADVANCES IN OPTICAL MOLECULAR PROBES}

Probes have been developed to perform molecular imaging to improve the specificity of disease detection. These probes typically use a fluorophore attached to an affinity or biochemical ligand. Optical imaging probes can be categorized into three groups based on function: non-specific, targeted, and activatable. Advantages and disadvantages of different classes of molecular probes are presented in Figure 5.

Non-specific fluorophores are used without a targeting ligand. Examples of nonspecific dyes include fluorescein, indocyanine green (ICG), and acriflavine. In general, these probes enhance contrast in mucosal morphology to identify pre-cancer and cancer. However, some dyes have a certain degree of intra- or extracellular localization; for example, acriflavine binds to nuclear materials. These fluorophores have low molecular weight $(<1 \mathrm{kD})$, allowing for efficient delivery via topical or intravenous administration. The usefulness of imaging using of these contrast agents is limited by non-specific background.

Affinity ligands that bind specifically to cell surface targets are called 'targeted-cellspecific probes,' and include whole antibodies, antibody fragments, short sequence peptides, aptamers, and small molecules. Antibodies have been used extensively to detect tumors [32-35] using well-established fluorophore labeling methods. However, antibodies have slow binding onset (hours to days) due to steric hindrance from their

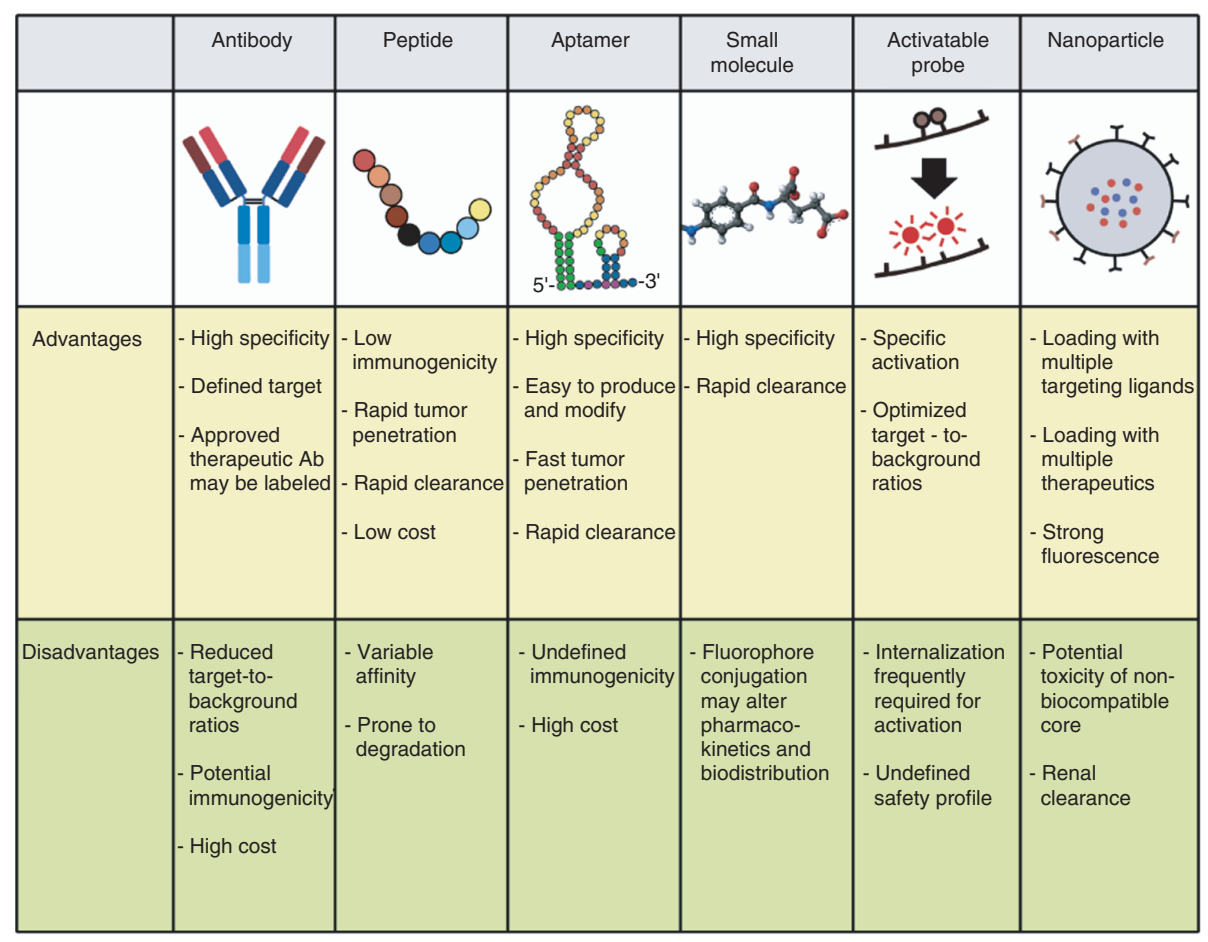

Figure 5. Advantages and disadvantages of molecular probe platforms. 
relatively large size $(150-160 \mathrm{kDa})$ and typical geometry as well as from certain properties including conformation, surface charge, hydrophobicity, and hydrophilicity [36-38]. Another major limitation of antibodies as probes is slow clearance due to prolonged half-life resulting in reduced target-to-background ratios. In addition, most antibodies incur some immunogenicity with repeated use. Antibody fragments are smaller in size $(\sim 50 \mathrm{kDa})$, resulting in more efficient tissue penetration and accumulation in tumor cells and faster clearance, while retaining the specificity of the parent antibody. These properties offer improved target-to-background ratios and reduced immunogenicity.

Peptides can be developed with good specificity, high affinity for cellular targets, and rapid binding kinetics (few minutes). Because they contain only a few amino acids, peptides are less likely to be immunogenic. These properties are compatible with targeted imaging using endoscopy in a busy clinical unit. Also, peptides have shorter clearance times and much lower production costs compared to antibodies. Phage display is a powerful approach to screen for peptide sequences [31, 39]. This unbiased technique uses methods of recombinant DNA technology to generate a highly diverse library to find a specific binder to cell surface targets. This screening technique is also helpful for identifying new protein targets expressed by tumor cells. Natural peptides have a short biological half-life due to rapid degradation by peptidase and protease enzymes in plasma and tissues. Thus, once key amino acid residues have been identified, most peptides are structurally modified to prolong their in vivo half-life. Examples of modification methods include introduction of D-amino acids, use of unusual amino acids or side chains, integration of amino alcohol, and acetylation or amination of the $\mathrm{N}$ - and $\mathrm{C}$ - termini [40].

Aptamers are single stranded DNA, RNA, or modified nucleic acids that are generally developed through an in vitro selection process, such as SELEX (systematic evolution of ligands by exponential enrichment). Aptamers have low molecular weight (3-20 kDa), high specificity, fast tissue penetration, and rapid clearance. In addition, they are easy to discover, produce, and modify. However, they are expensive to produce in large quantities, and tailored modifications further increase production costs. A number of aptamer-based therapeutics are currently in clinical trials and have yet to elicit immunogenicity [41, 42].

Small molecules can also be used for binding to specific cell receptors. For example, folic acids bind to folate receptors, which are over-expressed on proliferating cells and macrophages. These probes have high specificity and rapid uptake. However, due to their small size, their pharmacokinetics and/or biodistribution may become affected after conjugation with fluorophores.

Activatable or "smart probes" do not emit light in their native form, and release fluorescence only in the presence of specific enzymes. Hence, they are known as 'enzymespecific probes'. In general, these probes are less specific than targeted-cell-specific probes. They are frequently composed of multiple fluorophores attached on a polymer backbone. "Smart" probes have advantages that include a high target-to-background ratio, high loading capacity for fluorescent dyes, and ability to amplify fluorescence intensity upon multiple cleavage events. Smart probes can be activated by proteases, including 
cathepsins and matrix metalloproteinases (MMPs), that have elevated levels in a number of tumors. These proteolytic enzymes facilitate tissue invasion, metastasis, and angiogenesis [43, 44]. The use of an NIR Cathepsin K (CatK)- activatable probe was demonstrated in a mouse model of atherosclerosis and resected human artheromata [45]. The probe consists of multiple CatK peptide substrates, GHPGGPQGKC, serving as linkers between NIR Cy5.5 dyes and a poly-L-lysine-PEG polymer backbone. The peptide substrate undergoes cleavage between the two glycine residues in the presence of CatK. In another study, an MMP-2- activatable probe was tested in vitro using photoacoustic microscopy [46]. The probe contains the MMP-2 peptide substrate, GGPLGMLARH, linked with a chlorophyll derivative or natural photosynthetic bacteriochlorophyll. MMP2 cleaved the probe between the methionine and the glycine residues.

Several types of nanoparticles such as magnetic iron oxide, gold, quantum dots, and polymer nanoparticles have also been developed as non-specific contrast agents. Alternatively, these nanoparticles can also be used as molecule-specific probes by conjugating with targeting moieties, including peptides, antibodies, or aptamers. However, serious concerns about the potential toxicity of some nanoparticles such as quantum dots [47-50] have been raised. Therefore, nanoparticles should be thoroughly characterized in terms of toxicity, biodistribution, and pharmacokinetics before clinical use.

\section{RECENT ADVANCES IN ENDOSCOPIC MOLECULAR IMAGING}

By integrating with molecular probes, endoscopes and endomicroscopes may play an expanded role in the clinic. This section reviews recent findings that show potential applications of molecular imaging for disease detection in the clinical.

The two most common molecular probes that have been developed for clinical use are antibodies and peptides. Clinical use of antibodies as molecular probes has been widely explored. There are several known molecular targets for a variety of cancers, including epidermal growth factor receptor (EGFR), vascular endothelial growth factor (VEGF), and human epidermal growth factor receptor 2 (HER2/neu). Specific antibodies to these molecular targets have been established and successfully applied in the clinic for targeted cancer therapy. Alternatively, these antibodies can be utilized as targeted imaging probes.

EGFR is a transmembrane glycoprotein tyrosine kinase receptor that promotes tumor proliferation, invasion, metastasis, and neovascularization [51]. EGFR is overexpressed in roughly $25-94 \%$ of colorectal cancer cases [52, 53] and in most squamous cell carcinomas of the head and neck [54]. Cetuximab and panitumumab are examples of monoclonal antibodies that bind specifically to EGFR. In one study, FITClabeled EGFR antibodies were topically applied on excised human colonic specimens. The mean fluorescence of neoplasia was significantly higher than that of normal mucosa using confocal endomicroscopy [32].

VEGF is upregulated in tumor cells and function to promote angiogenesis. Bevacizumab is a well-known monoclonal antibody to VEGF that has been used to treat a number of solid tumors, including colorectal cancer [56] and head and neck tumors [57]. In one study, antibodies against VEGF and VEGFR-2 were labeled with Alexa Fluor 680. The imaging experiments were performed in colorectal mouse models (APC ${ }^{\mathrm{min}}$ mice and xenografts), and in excised patient specimens using bioluminescence 
imaging (IVIS) and confocal laser endomicroscopy [55]. Labeled antibody was injected to $\mathrm{APC}^{\mathrm{min}}$ mice via tail vein and endoscopic imaging was performed $24 \mathrm{~h}$ postinjection. Examples of nuclear, cytoplasmatic and membrane staining on confocal are shown in Figure 6A-C, respectively. When stained with fluorescently labeled VEGF antibodies, staining is seen in the tumor cell cytoplasm but not in the nuclei (Figure 6B). Figure 6D shows a surgical specimen of a human liver colorectal cancer metastasis. Figure $6 \mathrm{E}$ shows a confocal image of VEGF identifying the margins of a liver metastasis. Only the tumor (asterisk *) was stained, whereas normal liver (cross + ) revealed no signal. Confocal endomicroscopy using specific antibodies to VEGF showed a cytoplasmic distribution of VEGF that may be used for tumor detection. In another study, Bevacizumab-Cy5.5 conjugates were demonstrated in a mouse model of head and neck cancer. The labeled VEGF antibody was injected to tumor bearing mice via tail vein. Tumors were imaged $48 \mathrm{~h}$ post-injection and then resected. The result indicated tumor detection sensitivity of $80.9 \%$ and specificity of $91.7 \%$ [58].

Other antibodies used for head and neck cancer imaging include CD147 and transferrin receptor (TfR). CD147 is a membrane-spanning molecule that is highly expressed in head and neck tumor cells. Transferin receptor is a cell-membraneinternalizing receptor, which is responsible for iron sequestration and is overexpressed in many head and neck tumors. Anti-CD147 was conjugated with Cy5.5. The labeled anti-CD147 was injected into immunodeficient murine model bearing head and neck squamous cell carcinoma (HNSCC) via tail vein, and tumors were imaged using Leica stereomicroscope at 24, 48, 72, and $144 \mathrm{~h}$ after injection [59]. TfR antibody was labeled with Alexa-488. TfRNIR was injected into immunodeficient mice bearing HNSCC via tail vein, and animals were imaged using IVIS every 10-30 min up to at least $6 \mathrm{~h} \mathrm{[60].}$ The results indicated a potential use of anti-CD147 and TfR antibody for noninvasive head and neck tumor imaging.

Peptides play an important role as a class of molecular probes due to their safety, high specificity, and rapid binding kinetics. Alpha-v-beta-3 $\left(\alpha_{v} \beta_{3}\right)$ integrin is an important adhesion molecule in the regulation of angiogenesis. This integrin can be found at the end of newly formed blood vessels and on many tumor cells. Arginineglycine-aspartate (RGD) peptide is known to bind to $\alpha_{\mathrm{v}} \beta_{3}$ integrin and has been used to target $\alpha_{\mathrm{v}} \beta_{3}$ integrin. The cyclic RGD (cRGD) was conjugated to Cy5.5 or IRdye800CW for imaging of tumor angiogenesis [62]. In another study, a quenched cRGD molecule (RAFT-c(-RGDfK-)(4)-Cy5-SS-Q) was designed to be activated after being internalized [63].

The potential use of peptides has also been demonstrated in several pre-clinical and clinical studies. Using phage display, our group has developed several peptide sequences that are promising for molecular imaging and early detection of cancer. Recently, a fluorescently-labeled peptide QPIHPNNM was demonstrated in vivo using a wide-field small animal endoscope. The labeled QPI and control peptides were topically administered to polyps in distal rectal area. The distal rectal area was then washed and endoscopic imaging was performed after $5 \mathrm{~min}$ of incubation. The QPI peptide was shown to preferentially bind to dysplastic lesions in an Apc-mutation dependent $(C P C ; A p c)$ mouse model that spontaneously develops colonic adenomas, 
(a)

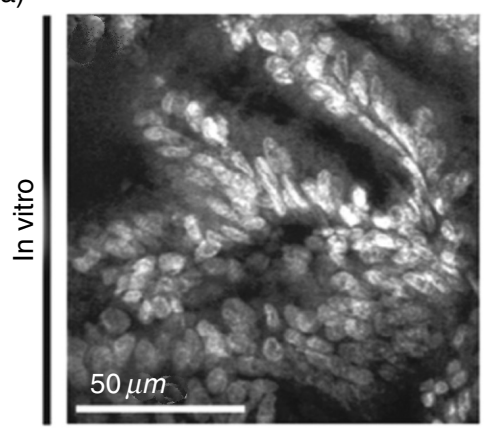

(c)

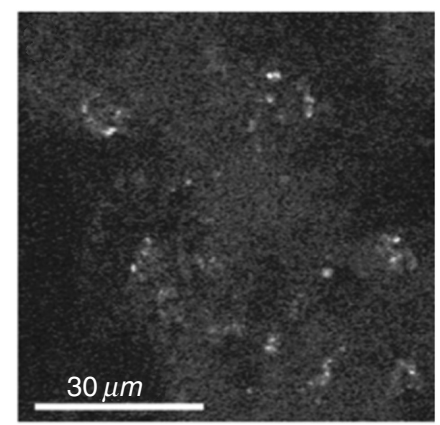

(e)

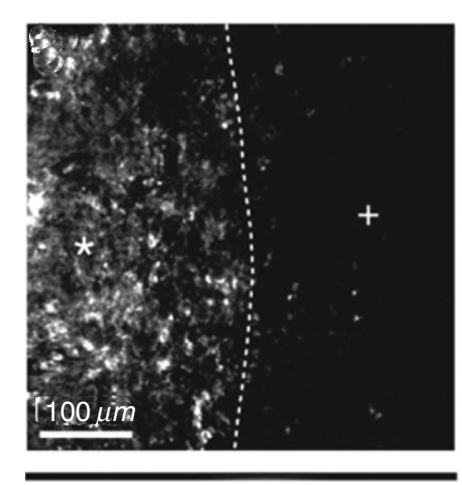

In vitro (b)

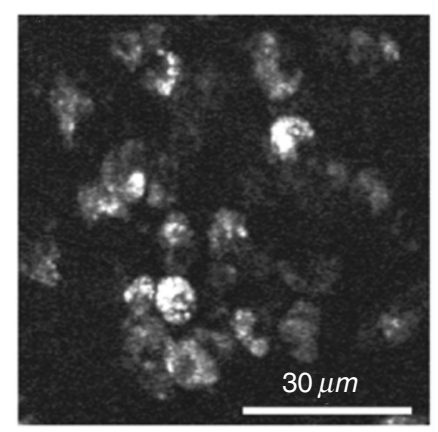

(d)

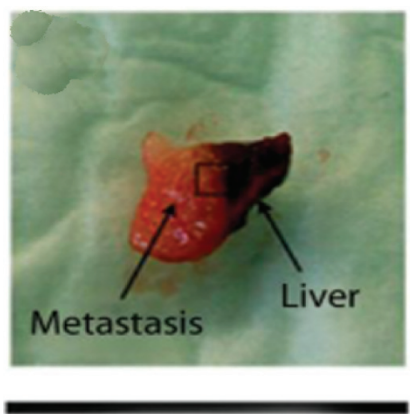

(f)

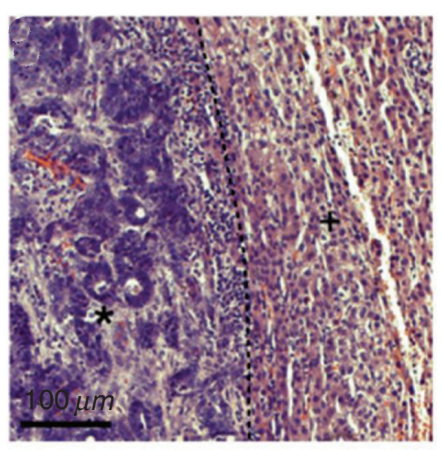

Ex vivo

Figure 6. Confocal images of vascular endothelial growth factor (VEGF) and its receptor (VEGFR-2) in the same biopsy specimen of a human colorectal adenocarcinoma. (A) Non-specific nuclear and cellular staining using acriflavine. (B) VEGF-specific staining using labeled antibodies. (C) VEGFR-2-specific staining with labeled antibodies against the receptor. (D) Resection specimen of a human liver colorectal cancer metastasis. (E) Molecular imaging of VEGF identifies tumor margins. (F) Histology (H\&E) of the same biopsy specimen. Used with permission [55]. 
but not to hyperplastic lesions in a mutant Kras mouse model [61]. The QPI peptide showed positive binding to multiple colonic adenomas (Figure 7A) and a single adenoma (Figure 7B) in vivo. The control peptide, GGGAGGGA, showed minimal binding (Figure $7 \mathrm{C}$ ). In addition, the targeted peptide also showed minimal binding in a wild-type (control) mouse (Figure 7D) and the hyperplastic epithelium in a mutant Kras mouse model (Figure 7E).

In a recent study, multiple peptides labeled with different fluorescent dyes exhibited enhanced binding specificity and sensitivity in the $C P C$;Apc mouse model with a multispectral scanning fiber endoscope (SFE) [8] . The peptides KCCFPAQ, AKPGYLS, and LTTHYKL that bind specifically to colonic dysplasia were identified with in vivo phage display technique using $C P C ; A p c$ mouse model. The peptides were applied topically, endoscopic imaging was performed after $5 \mathrm{~min}$ of incubation, and specific binding of each peptide to colonic dysplasia was demonstrated (Figure 8A-C). The corresponding white light images are shown below (Figure 8D-F). The KCCFPAQDEAC and AKPGYLS-TAMRA peptides showed greater fluorescence intensity consistent with specific binding, compared to the control peptides GGGAGGG-DEAC and GGGAGGG-TAMRA with statistical significance. This study demonstrated the integration of a multispectral imaging system and multiple molecular probes that have potential to simultaneously visualize more than one gene target and differentiate the contribution of individual gene targets that are overexpressed in neoplasia. This potential may contribute to personalized imaged-guided therapy. Multispectral peptide probes can also be used to localize colonic dysplasia for early detection and improve margin detection for tumor resection.

(a)

(b)

(c)

(d)

(e)

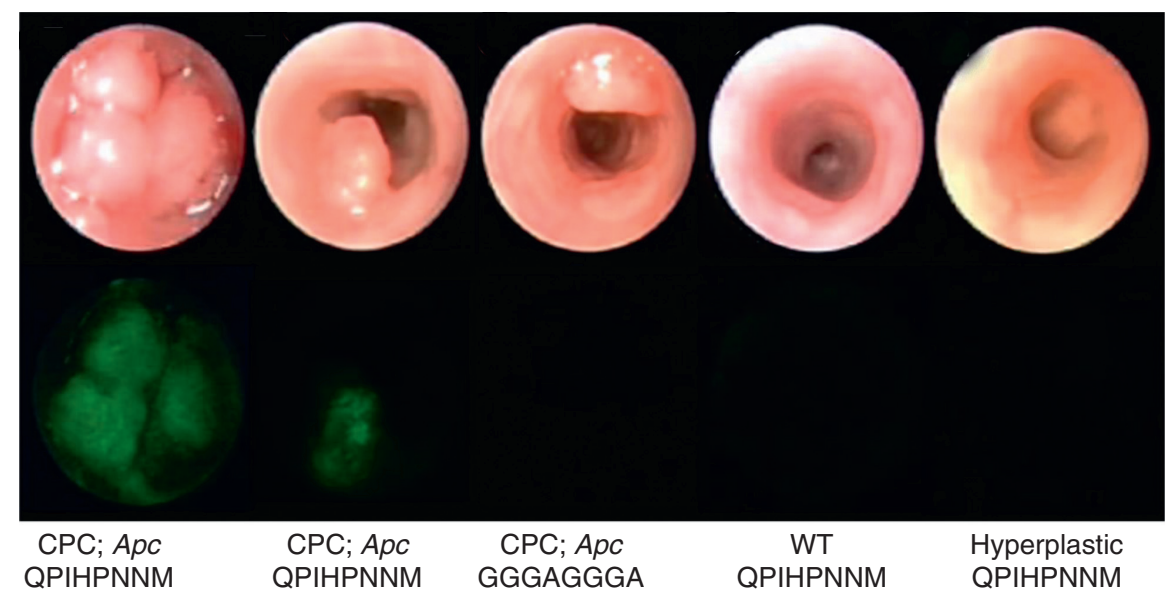

Figure 7. Images from wide-field endoscopy videos after application of fluorescence-labeled peptides. The top and bottom rows represent frames from white light and fluorescence, respectively. Used with permission [61]. 
(a)

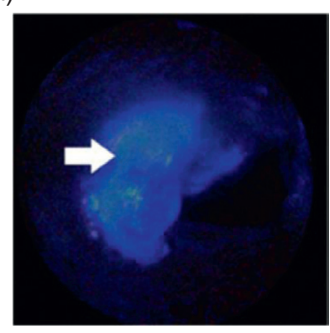

(d)

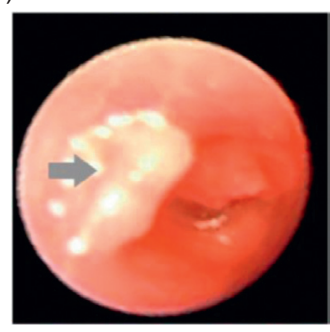

(g) (b)

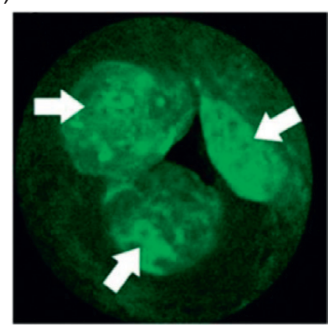

(e)

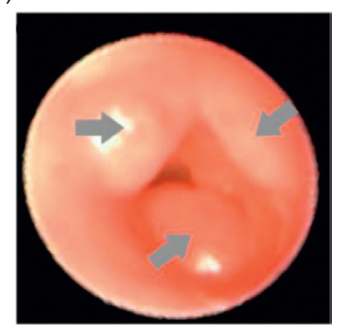

(c)

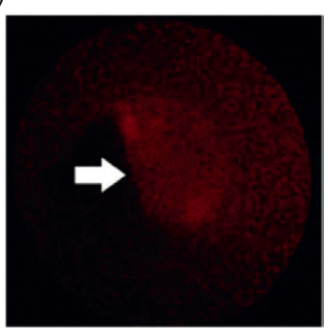

(f)

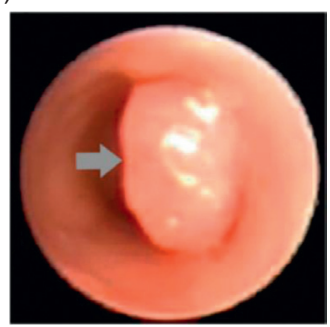

(h)
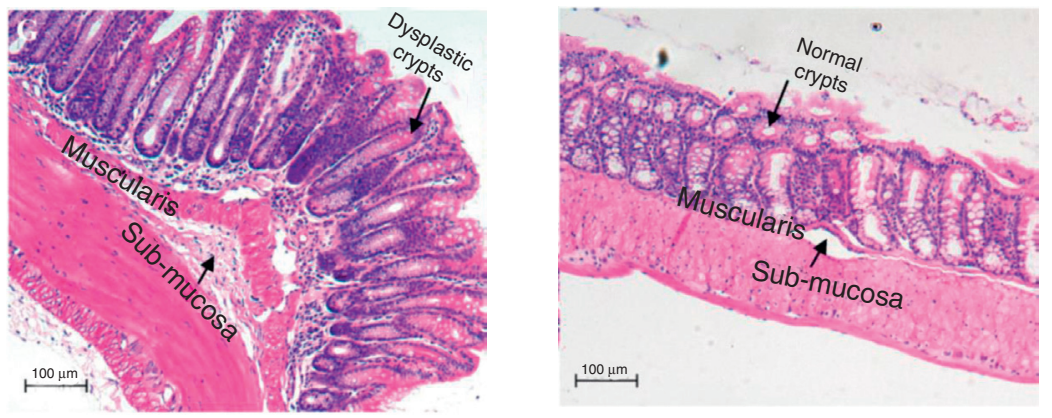

Figure 8. Wide-field fluorescence images of colonic adenoma collected with the multispectral scanning fiber endoscope after separate administration of peptides (A) KCCFPAQ-DEAC, (B) AKPGYLS-TAMRA, and (C) LTTHYKL-CF633. (D-F) The corresponding white light images. Histology $(\mathrm{H} \& \mathrm{E})$ of $(\mathrm{G})$ adenoma and $(\mathrm{H})$ normal colonic mucosa. Used with permission [8].

\section{DISCUSSION}

A variety of novel endoscope and endomicroscope designs are being developed for real time imaging in pre-clinical and clinical applications. Conventional WLE provides a large FOV of the mucosal surface and are used as the standard of care for screening and surveillance. Advanced wide-field endoscopes such as AFI and NBI have been developed with enhanced spectral features. However, results for improved disease detection using AFI and NBI compared to WLE are variable, and depend on the study. 
SFE is another wide-field endoscope design that has recently been developed for multispectral fluorescence imaging.

Confocal endomicroscopes have been employed to achieve imaging of sub-cellular features in vivo in numerous clinical studies. Currently, the single axis designs are limited by short WD, small FOV, and superficial tissue penetration depths with $488 \mathrm{~nm}$ excitation. Recently, there have been significant efforts to develop endomicroscopes that have improved tissue penetration depths without compromising in resolution, such as the dual-axes confocal and multiphoton endomicroscopes. These instruments are capable of performing optical sectioning in real time, which potentially allows for disease detection at the point of care. Two-photon fluorescence endomicroscopy is also a powerful technology for imaging of unstained biological tissues. Besides providing high-resolution, in vivo images, this label free instrument has shown great medical diagnostic promise. However, the maximum imaging depth is limited to $\sim 1 \mathrm{~mm}$ [27].

A number of molecular probes have been developed to improve disease detection capability and enhance the clinical utility of existing endoscopes. Targeting agents are designed to achieve high specificity, strong signal, pharmacokinetic profile compatible with clinical use, and high target-to-background ratios. In addition, safety is a key requirement for translating these exogenous agents for human use. The process of developing imaging agents is analogous to drug development process that is very costly, high risk, and time consuming. It takes about 10 to 17 years and nearly $\$ 0.8-\$ 1.7$ billion to bring a therapeutic drug to market [64], while the current estimate of cost to bring a new imaging agent to the market is about $\$ 100$ to $\$ 500$ million [65]. To date, there are only a limited number of fluorescence dyes, such as fluorescein isothiocyanate (FITC) and indocyanine green (ICG), approved by FDA. In addition, 5-aminolevulinic acid (5-ALA) was approved in the European Union for cystoscopy [66].

Currently, novel endoscopic imaging methods are being developed taking advantage of the rapid technological advances in micro-optics, scanning and actuation mechanisms, light sources, and emerging molecular probes. Future endoscopic instruments are likely to include multiple modalities such as 1) high-resolution whitelight imaging for rapid wide-field observation, 2) high-contrast fluorescence imaging for highlighting disease regions using molecular probes, and 3) microscopic imaging to validate receptor status at a sub-cellular level. These future endoscopes promise to allow physicians to make more accurate clinical decisions, reduce time for diagnosis, guide tissue sampling, and ultimately improve patient outcomes.

\section{CONCLUSION}

Endoscopes are important tools for imaging the mucosa of hollow organs in vivo for screening and surveillance of several common cancers in organs such as esophagus, stomach, colon, and rectum. Rapid technological advances in light sources, microoptics, optical fibers, and miniature scanners will further expand these capabilities through multi-spectral image collection, greater access to internal organs, better tissue penetration, and 3D volumetric imaging. The addition of molecular probes provides a new feature that allows clinicians to visualize pre-cancerous and cancerous lesions based on their expressed protein targets rather than on morphology alone. These 
innovative target-specific molecular probes promise to significantly improve the specificity of disease detection, and may assist physicians to detect cancer at an earlier time point before gross anatomical changes occur. Other potential benefits of these developments include imaged guide therapy, targeted therapy and personalized medicine.

\section{ACKNOWLEDGEMENTS}

The authors would like to acknowledge funding support from the US National Institutes of Health through U54 CA163059, U54 CA13642, R01 CA142750, and P50 CA93990. We would also like to thank Dr. Victoria L. Murray for proofreading this manuscript.

\section{CONFLICT OF INTEREST}

The authors have no conflicts or financial relations to disclose.

\section{REFERENCES}

[1] Fass L. Imaging and cancer: a review. Molecular oncology, 2008, 2(2):115-152.

[2] Lee CM, Engelbrecht CJ, Soper TD, Helmchen F, Seibel EJ. Scanning fiber endoscopy with highly flexible, $1 \mathrm{~mm}$ catheterscopes for wide-field, full-color imaging. Journal of Biophotonics, 2010, 3(5-6):385-407.

[3] Kim P, Puoris'haag M, Côté D, Lin CP, Yun SH. In vivo confocal and multiphoton microendoscopy Journal of Biomedical Optics, 2008, 13:010501.

[4] Soetikno RM, Kaltenbach T, Rouse RV, Park W, Maheshwari A, Sato T, Matsui S, Friedland S. Prevalence of nonpolypoid (flat and depressed) colorectal neoplasms in asymptomatic and symptomatic adults. JAMA: the journal of the American Medical Association, 2008, 299(9):1027-1035.

[5] Kato M, Uedo N, Ishihara R, Kizu T, Chatani R, Inoue T, Masuda E, Tatsumi K, Takeuchi Y, Higashino $\mathrm{K}$. Analysis of the color patterns of early gastric cancer using an autofluorescence imaging video endoscopy system. Gastric cancer, 2009, 12(4):219-224.

[6] Uedo N, Higashino K, Ishihara R, Takeuchi Y, Iishi H. Diagnosis of colonic adenomas by new autofluorescence imaging system: a pilot study. Digestive Endoscopy, 2007, 19:S134-S138.

[7] Chandler JE, Lee CM, Babchanik AP, Melville CD, Saunders MD, Seibel EJ. Evaluation of a novel, ultrathin, tip-bending endoscope in a synthetic force-sensing pancreas with comparison to medical guide wires. Medical Devices: Evidence and Research, 2011, 5:1-12.

[8] Miller SJ, Lee CM, Joshi BP, Gaustad A, Seibel EJ, Wang TD. Targeted detection of murine colonic dysplasia in vivo with flexible multispectral scanning fiber endoscopy. Journal of Biomedical Optics 2012, 17:021103.

[9] Kiesslich R, Burg J, Vieth M, Gnaendiger J, Enders M, Delaney P, Polglase A, McLaren W, Janell D, Thomas S. Confocal laser endoscopy for diagnosing intraepithelial neoplasias and colorectal cancer in vivo. Gastroenterology, 2004, 127(3):706-713.

[10] Kakeji Y, Yamaguchi S, Yoshida D, Tanoue K, Ueda M, Masunari A, Utsunomiya T, Imamura M, Honda H, Maehara Y. Development and assessment of morphologic criteria for diagnosing gastric cancer using confocal endomicroscopy: an ex vivo and in vivo study. Endoscopy, 2006, 38(9):886-890.

[11] Kuiper T, van den Broek F, van Eeden S, Fockens P, Dekker E. Feasibility and Accuracy of Confocal Endomicroscopy in Comparison With Narrow-Band Imaging and Chromoendoscopy for the Differentiation of Colorectal Lesions. The American journal of gastroenterology, 2012, 107(4):543-550. 
[12] Shahid MW, Buchner AM, Coron E, Woodward TA, Raimondo M, Dekker E, Fockens P, Wallace MB. Diagnostic accuracy of probe-based confocal laser endomicroscopy in detecting residual colorectal neoplasia after EMR: a prospective study. Gastrointestinal Endoscopy, 2011, 75(3):525-533.

[13] Giovannini M, Bories E, Monges G, Pesenti C, Caillol F, Delpero J. Results of a phase I-II study on intraductal confocal microscopy (IDCM) in patients with common bile duct (CBD) stenosis. Surgical endoscopy, 2011:1-7.

[14] Meining A, Shah R, Slivka A, Pleskow D, Chuttani R, Stevens P, Becker V, Chen Y. Classification of probe-based confocal laser endomicroscopy findings in pancreaticobiliary strictures. Endoscopy, 2012, 44(3):251.

[15] Hsiung PL, Hardy J, Friedland S, Soetikno R, Du CB, Wu AP, Sahbaie P, Crawford JM, Lowe AW, Contag $\mathrm{CH}$. Detection of colonic dysplasia in vivo using a targeted heptapeptide and confocal microendoscopy. Nature medicine, 2008, 14(4):454-458.

[16] Piyawattanametha W, Ra H, Mandella MJ, Loewke K, Wang TD, Kino GS, Solgaard O, Contag CH. 3-D near-infrared fluorescence imaging using an MEMS-based miniature dual-axis confocal microscope. Selected Topics in Quantum Electronics, IEEE Journal of, 2009, 15(5):1344-1350.

[17] Piyawattanametha W, Ra H, Qiu Z, Friedland S, Liu JTC, Loewke K, Kino GS, Solgaard O, Wang TD, Mandella MJ. In vivo near-infrared dual-axis confocal microendoscopy in the human lower gastrointestinal tract. Journal of Biomedical Optics, 2012, 17:021102.

[18] Liu JTC, Mandella MJ, Ra H, Wong LK, Solgaard O, Kino GS, Piyawattanametha W, Contag CH, Wang TD. Miniature near-infrared dual-axes confocal microscope utilizing a two-dimensional microelectromechanical systems scanner. Opt. Lett., 2007, 32(3):256-258.

[19] Provenzano PP, Eliceiri KW, Keely PJ. Multiphoton microscopy and fluorescence lifetime imaging microscopy (FLIM) to monitor metastasis and the tumor microenvironment. Clinical and Experimental Metastasis, 2009, 26(4):357-370.

[20] Dela Cruz JM, McMullen JD, Williams RM, Zipfel WR. Feasibility of using multiphoton excited tissue autofluorescence for in vivo human histopathology. Biomedical optics express, 2010, 1(5):1320-1330.

[21] Knorr F, Yankelevich DR, Liu J, Wachsmann-Hogiu S, Marcu L. Two-photon excited fluorescence lifetime measurements through a double-clad photonic crystal fiber for tissue micro-endoscopy. Journal of Biophotonics, 2012, 5(1):14-19.

[22] Rivera DR, Brown CM, Ouzounov DG, Webb WW, Xu C. Use of a lensed fiber for a large-field-ofview, high-resolution, fiber-scanning microendoscope. Optics letters, 2012, 37(5):881-883.

[23] Tang S, Jung W, McCormick D, Xie T, Su J, Ahn YC, Tromberg BJ, Chen Z. Design and implementation of fiber-based multiphoton endoscopy with microelectromechanical systems scanning. Journal of Biomedical Optics, 2009, 14:034005.

[24] Murari K, Zhang Y, Li S, Chen Y, Li MJ, Li X. Compensation-free, all-fiber-optic, two-photon endomicroscopy at $1.55 \mu \mathrm{m}$. Optics letters, 2011, 36(7):1299-1301.

[25] Wu Y, Leng Y, Xi J, Li X. Scanning all-fiber-optic endomicroscopy system for 3D nonlinear optical imaging of biological tissues. Optics express, 2009, 17(10):7907-7915.

[26] Bao H, Boussioutas A, Reynolds J, Russell S, Gu M. Imaging of goblet cells as a marker for intestinal metaplasia of the stomach by one-photon and two-photon fluorescence endomicroscopy. Journal of Biomedical Optics, 2009, 14:064031.

[27] Huland DM, Brown CM, Howard SS, Ouzounov DG, Pavlova I, Wang K, Rivera DR, Webb WW, Xu C. In vivo imaging of unstained tissues using long gradient index lens multiphoton endoscopic systems. Biomedical optics express, 2012, 3(5):1077-1085.

[28] Xi J, Chen Y, Zhang Y, Murari K, Li MJ, Li X. Integrated multimodal endomicroscopy platform for simultaneous en face optical coherence and two-photon fluorescence imaging. Optics letters, 2012, 37(3):362-364.

[29] König K, Ehlers A, Riemann I, Schenkl S, Bückle R, Kaatz M. Clinical two-photon microendoscopy. Microscopy research and technique, 2007, 70(5):398-402. 
[30] König K, Bückle R, Weinigel M, Elsner P, Kaatz M. Clinical multiphoton tomography and clinical two-photon microendoscopy. Paper presented at: SPIE BiOS: Biomedical Optics 2009.

[31] Shao P, Shi W, Hajireza P, Zemp RJ. Combined optical-resolution photoacoustic and fluorescence micro-endoscopy. Paper presented at: Proceedings of SPIE 2012.

[32] Goetz M, Ziebart A, Foersch S, Vieth M, Waldner MJ, Delaney P, Galle PR, Neurath MF, Kiesslich R. In vivo molecular imaging of colorectal cancer with confocal endomicroscopy by targeting epidermal growth factor receptor. Gastroenterology, 2010, 138(2):435-446.

[33] Lee JH, Huh YM, Jun Y, Seo J, Jang J, Song HT, Kim S, Cho EJ, Yoon HG, Suh JS. Artificially engineered magnetic nanoparticles for ultra-sensitive molecular imaging. Nature medicine, 2006, 13(1):95-99.

[34] Ogawa M, Kosaka N, Choyke PL, Kobayashi H. In vivo molecular imaging of cancer with a quenching near-infrared fluorescent probe using conjugates of monoclonal antibodies and indocyanine green. Cancer research, 2009, 69(4):1268.

[35] Sharkey RM, Cardillo TM, Rossi EA, Chang CH, Karacay H, McBride WJ, Hansen HJ, Horak ID, Goldenberg DM. Signal amplification in molecular imaging by pretargeting a multivalent, bispecific antibody. Nature medicine, 2005, 11(11):1250-1255.

[36] Bachmann MF, Jennings GT. Vaccine delivery: a matter of size, geometry, kinetics and molecular patterns. Nature Reviews Immunology, 2010, 10(11):787-796.

[37] Boehr DD, Nussinov R, Wright PE. The role of dynamic conformational ensembles in biomolecular recognition. Nature chemical biology, 2009, 5(11):789-796.

[38] Kwon YS, Cho YS, Yoon TJ, Kim HS, Choi MG. Recent advances in targeted endoscopic imaging: Early detection of gastrointestinal neoplasms. World journal of gastrointestinal endoscopy, 2012, 4(3):57.

[39] Brissette R, Prendergast JKA, Goldstein NI. Identification of cancer targets and therapeutics using phage display. Current Opinion in Drug Discovery and Development, 2006, 9(3):363.

[40] Lee S, Xie J, Chen X. Peptides and peptide hormones for molecular imaging and disease diagnosis. Chemical reviews, 2010, 110(5):3087.

[41] Gilbert JC, DeFeo-Fraulini T, Hutabarat RM, Horvath CJ, Merlino PG, Marsh HN, Healy JM, BouFakhreddine S, Holohan TV, Schaub RG. First-in-human evaluation of anti-von Willebrand factor therapeutic aptamer ARC1779 in healthy volunteers. Circulation, 2007, 116(23):2678-2686.

[42] Macugen A, Apte R, Modi M, Masonson H, Patel M, Whitfield L, Adamis A. Pegaptanib 1-year systemic safety results from a safety-pharmacokinetic trial in patients with neovascular age-related macular degeneration. Ophthalmology, 2007, 114(9):1702.

[43] Kessenbrock K, Plaks V, Werb Z. Matrix metalloproteinases: regulators of the tumor microenvironment. Cell, 2010, 141(1):52-67.

[44] Mohamed MM, Sloane BF. Cysteine cathepsins: multifunctional enzymes in cancer. Nature Reviews Cancer, 2006, 6(10):764-775.

[45] Jaffer FA, Kim DE, Quinti L, Tung CH, Aikawa E, Pande AN, Kohler RH, Shi GP, Libby P, Weissleder R. Optical visualization of cathepsin $\mathrm{K}$ activity in atherosclerosis with a novel, protease-activatable fluorescence sensor. Circulation, 2007, 115(17):2292-2298.

[46] Green AH, Norris JR, Wang J, Xie Z, Zhang HF, La Riviere PJ. In vitro testing of a protease-sensitive contrast agent for optoacoustic imaging. Journal of Biomedical Optics, 2010, 15:021315.

[47] Ballou B, Lagerholm BC, Ernst LA, Bruchez MP, Waggoner AS. Noninvasive imaging of quantum dots in mice. Bioconjugate Chemistry, 2004, 15(1):79-86.

[48] Hardman R. A toxicologic review of quantum dots: toxicity depends on physicochemical and environmental factors. Environmental health perspectives, 2006, 114(2):165.

[49] Kirchner C, Liedl T, Kudera S, Pellegrino T, Javier AM, Gaub HE, Stölzle S, Fertig N, Parak WJ. Cytotoxicity of colloidal CdSe and CdSe/ZnS nanoparticles. Nano Letters, 2005, 5(2):331-338. 
[50] Mancini MC, Kairdolf BA, Smith AM, Nie S. Oxidative quenching and degradation of polymerencapsulated quantum dots: new insights into the long-term fate and toxicity of nanocrystals in vivo. Journal of the American Chemical Society, 2008, 130(33):10836-10837.

[51] Herbst RS, Shin DM. Monoclonal antibodies to target epidermal growth factor receptor-positive tumors. Cancer, 2002, 94(5):1593-1611.

[52] Ciardiello F, Tortora G. EGFR antagonists in cancer treatment. New England Journal of Medicine, 2008, 358(11):1160-1174.

[53] Normanno N, De Luca A, Bianco C, Strizzi L, Mancino M, Maiello MR, Carotenuto A, De Feo G, Caponigro F, Salomon DS. Epidermal growth factor receptor (EGFR) signaling in cancer. Gene, 2006, 366(1):2-16.

[54] Pomerantz RG, Grandis JR. The epidermal growth factor receptor signaling network in head and neck carcinogenesis and implications for targeted therapy. Paper presented at: Seminars in oncology 2004.

[55] Foersch S, Kiesslich R, Waldner MJ, Delaney P, Galle PR, Neurath MF, Goetz M. Molecular imaging of VEGF in gastrointestinal cancer in vivo using confocal laser endomicroscopy. Gut, 2010, 59(8):1046-1055.

[56] Chau I, Cunningham D. Treatment in advanced colorectal cancer: what, when and how\&quest. British journal of cancer, 2009, 100(11):1704-1719.

[57] Cohen EEW, Davis DW, Karrison TG, Seiwert TY, Wong SJ, Nattam S, Kozloff MF, Clark JI, Yan DH, Liu W. Erlotinib and bevacizumab in patients with recurrent or metastatic squamous-cell carcinoma of the head and neck: a phase I/II study. The lancet oncology, 2009, 10(3):247-257.

[58] Withrow KP, Newman JR, Skipper JB, Gleysteen JP, Magnuson JS, Zinn K, Rosenthal EL. Assessment of bevacizumab conjugated to Cy5. 5 for detection of head and neck cancer xenografts. Technology in cancer research \& treatment, 2008, 7(1):61-66.

[59] Newman JR, Gleysteen JP, Barañano CF, Bremser JR, Zhang W, Zinn KR, Rosenthal EL. Stereomicroscopic fluorescence imaging of head and neck cancer xenografts targeting CD147. Cancer biology \& therapy, 2008, 7(7):1063.

[60] Shan L, Hao Y, Wang S, Korotcov A, Zhang R, Wang T, Califano J, Gu X, Sridhar R, Bhujwalla ZM. Visualizing head and neck tumors in vivo using near-infrared fluorescent transferrin conjugate. Molecular Imaging, 2008, 7(1):42-49.

[61] Miller SJ, Joshi BP, Feng Y, Gaustad A, Fearon ER, Wang TD. In vivo fluorescence-based endoscopic detection of colon dysplasia in the mouse using a novel Peptide probe. PloS one, 2011,6(3):e17384.

[62] Chen K, Xie J, Chen X. RGD-human serum albumin conjugates as efficient tumor targeting probes. Molecular Imaging, 2009, 8(2):65.

[63] Jin ZH, Razkin J, Josserand V, Boturyn D, Grichine A, Texier I, Favrot MC, Dumy P, Coll JL. In vivo noninvasive optical imaging of receptor-mediated RGD internalization using self-quenched Cy5labeled RAFT-c (-RGDfK-)(4). Molecular Imaging, 2007, 6(1):43.

[64] Hoffman JM, Gambhir SS, Kelloff GJ. Regulatory and Reimbursement Challenges for Molecular Imaging 1. Radiology, 2007, 245(3):645-660.

[65] Nunn AD. The cost of developing imaging agents for routine clinical use. Investigative radiology, 2006, 41(3):206-212.

[66] Ahmad S, Aboumarzouk O, Somani B, Nabi G, Kata SG. Oral 5-aminolevulinic acid in simultaneous photodynamic diagnosis of upper and lower urinary tract transitional cell carcinoma-a prospective audit. BJU international, 2012:1-5. 



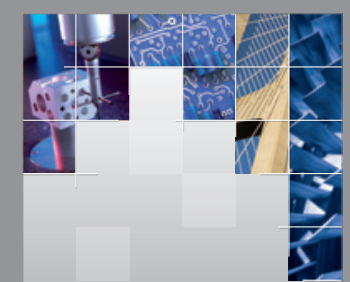

\section{Enfincering}
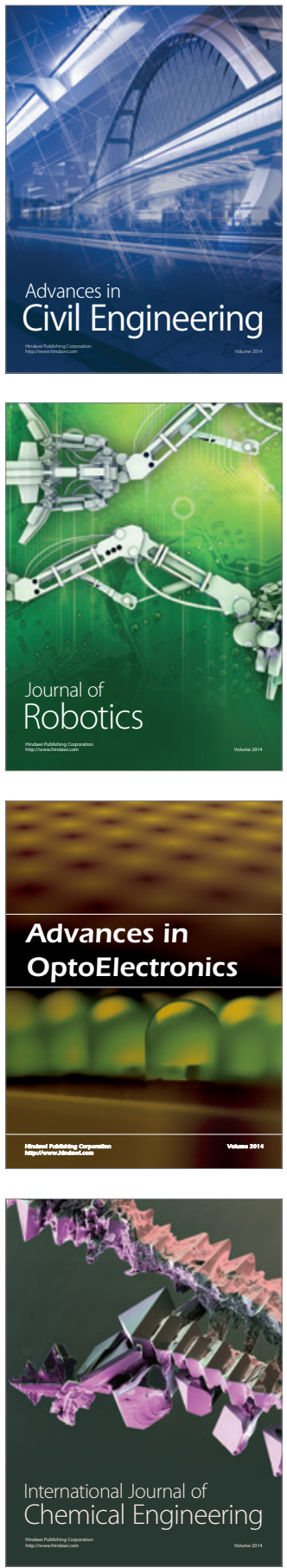

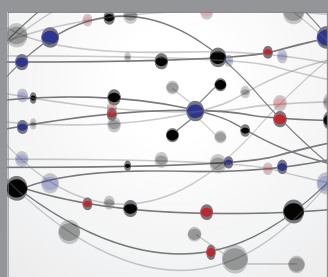

The Scientific World Journal

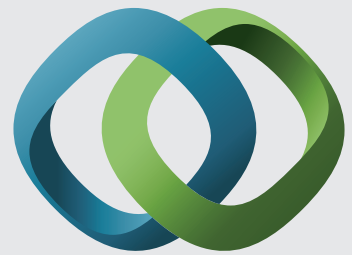

\section{Hindawi}

Submit your manuscripts at

http://www.hindawi.com
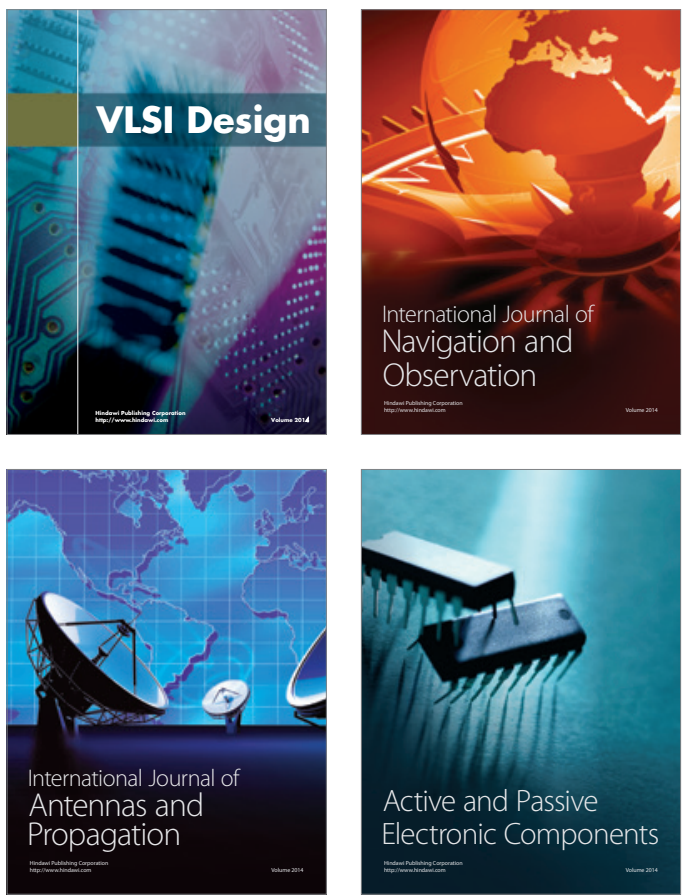
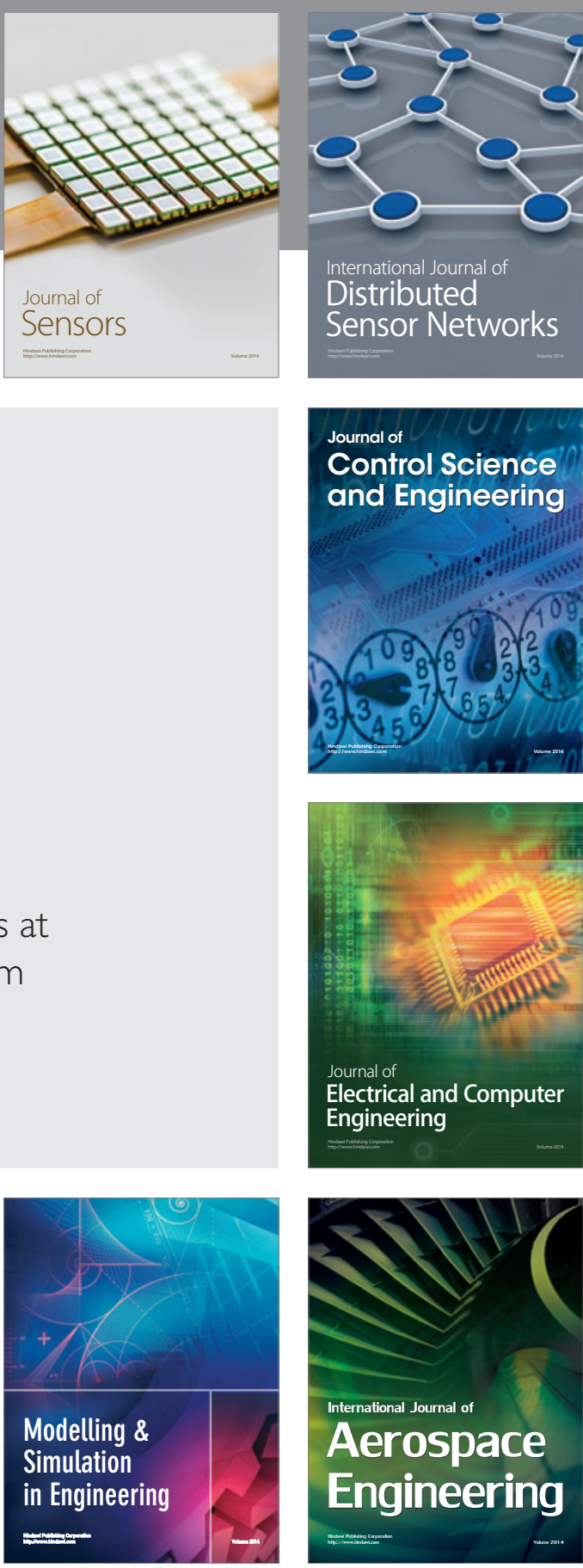

International Journal of

Distributed

Sensor Networks

Journal of

Control Science

and Engineering
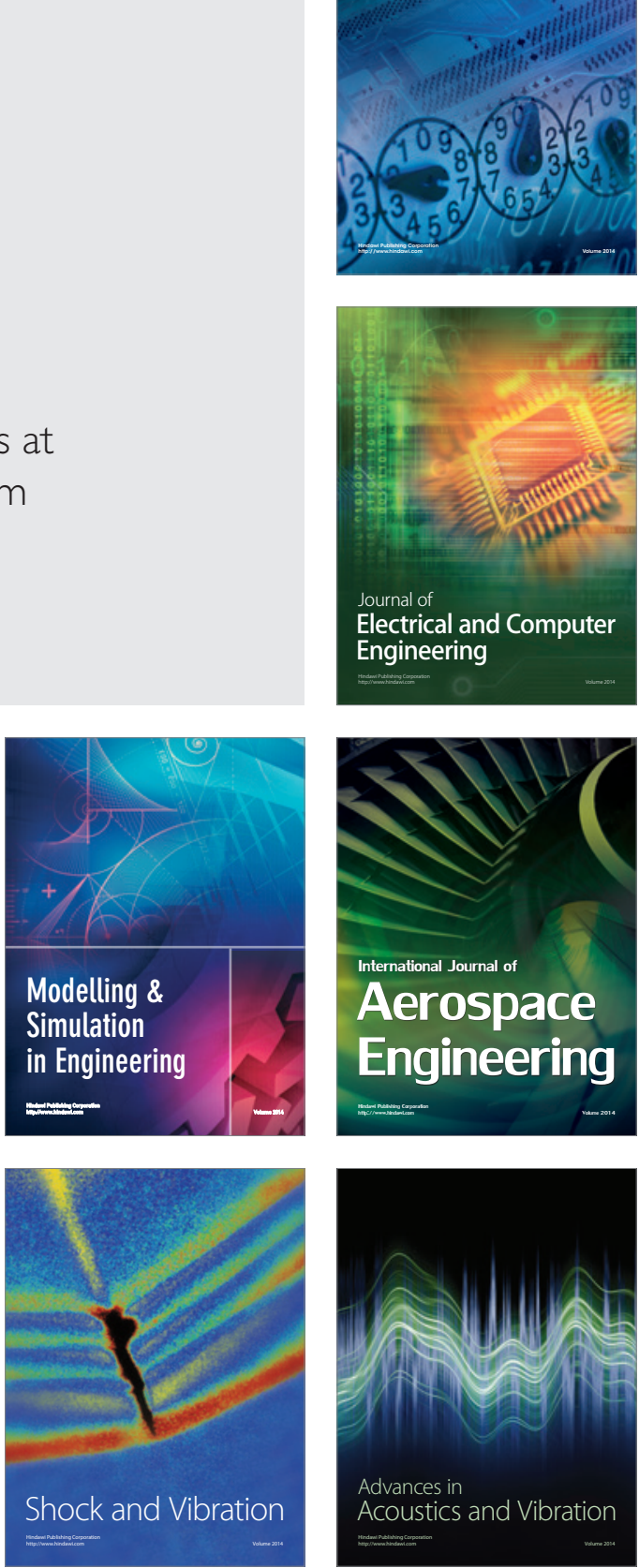